\title{
Narrativa autobiográfica en el cine: una alternativa para la enseñanza de la Historia Reciente
}

Autobiographical narrative cinema: an alternative for teaching recent history

Sabrina Martino Ermantraut ${ }^{*}$

Vanesa Gregorini**

\section{RESUMEN}

La presente propuesta busca analizar la construcción de la narrativa autobiográfica por medio del cine, sus posibilidades en el abordaje de la historia reciente así como el abanico de horizontes que se abren a partir de pensar su uso en el aula. Para ello, nos nutrimos de la microhistoria, perspectiva que destaca los aspectos cotidianos y las experiencias personales como elementos que iluminan un contexto más amplio. Desde este enfoque, y en pos de trabajar el vínculo entre cine, autobiografía e historia, seleccionamos tres películas cuyos directores recuperan hechos vividos en su infancia y los recrean desde el presente, aportando su singular mirada sobre la historia reciente de Argentina, Chile y Brasil. Estos relatos cinematográficos in-

\section{Abstract}

The present proposal seeks to analyze the construction of autobiographical narrative through the cinema, its possibilities in the approach to recent history as well as the range of horizons that are opened from thinking its use in the classroom. To that end, we draw on micro-history, perspective that emphasizes the everyday aspects and personal experiences as elements that illuminate a broader context. From this approach, and in order to work the link between film, autobiography and history, we selected three films whose directors retrieve facts lived in their childhoods and recreate them from the present, bringing their view of the recent history of Argentina, Chile and Brazil. These film narratives include, in the narration

\footnotetext{
* Doctoranda en Ciencias de la Educación, Universidad Nacional de La Plata. Docente en la Facultad de Ciencias Humanas, Universidad Nacional de La Pampa. Miembro del Instituto de Investigación en Humanidades y Ciencias Sociales. Becaria de Conicet, Buenos Aires, Argentina. sabrinaerma@yahoo.com.ar

** Doctoranda en Ciencias de la Educación, Universidad Nacional de La Plata. Docente en la Facultad de Ciencias Humanas, Universidad Nacional del Centro de la Provincia de Buenos Aires. Miembro del Centro Interdisciplinario de Estudios Políticos, Sociales y Jurídicos. Becaria de Conicet, Buenos Aires, Argentina. vanegregorini@yahoo.com.ar
} 
cluyen, en la narración de la experiencia, elementos ficcionales, recuerdos y olvidos, habilitando la reconstrucción de la memoria personal y colectiva.

Palabras clave: autobiografía; cine; Historia. of experience, fictional elements, memories and forgettings, enabling the reconstruction of a personal and collective memory.

Keywords: autobiography; cinema; History.

En el presente artículo nos proponemos traer a la reflexión una mirada singular sobre la Historia reciente, intentando realizar una triangulación entre cine, autobiografía y educación. Para esto, seleccionamos tres films y analizamos algunas entrevistas efectuadas a sus directores. Las películas escogidas presentan, por lo menos, los siguientes puntos en común: sus relatos se sitúan en un contexto que evoca las últimas dictaduras militares en Argentina, Chile y Brasil; ${ }^{1}$ están narrados desde las vivencias de un niño y retoman elementos autobiográficos, recuerdos e imágenes de la infancia de sus realizadores.

De este modo, la mirada microscópica y la perspectiva de los niños sobre el pasado reciente se conjugan para aportar una reconstrucción histórica singular que refleja la fructífera producción que puede engendrar el vínculo entre cine y la narrativa autobiográfica. Además, es nuestra intención evidenciar la significatividad de este análisis para la construcción de una historia colectiva, de la memoria histórica y de la identidad social, lo que conlleva trasladar estas implicancias al ámbito educativo, extendiendo de manera reflexiva la posibilidad de utilizar el cine con elementos autobiográficos en la enseñanza.

\section{UNA MIRADA MICROSCÓPICA}

De un tiempo a esta parte, el desarrollo de renovadas corrientes historiográficas dentro de la Historia social y cultural nos ha ayudado a comprender que los procesos históricos de larga duración pueden ser analizados partiendo de la historia de personajes individuales o de las perspectivas y acciones de aquellos sujetos que, si bien no figuran en los libros de Historia, tuvieron un gran protagonismo en el devenir de los acontecimientos. Partiendo de esta perspectiva, que otorga relevancia a la narrativa ${ }^{2}$ y a la acción de los sujetos individuales dentro de un contexto, interesa analizar en este artículo las películas Infancia clandestina (2011), del argentino Benjamín Ávila; Machuca 
(2004), del chileno Andrés Wood y O ano em que meus pais saíram de férias (2006), del brasileño Cao Hamburger.

Infancia clandestina (2011) nos ofrece una mirada particular sobre uno de los procesos históricos que marcaron a distintas generaciones en Argentina: la última dictadura militar (1976-1983). Se trata de una historia que ubica la lupa en un niño y en la vida cotidiana de su familia, permitiendo salir del estereotipo que domina el género de películas sobre el periodo referido, cuyo eje suele situarse en los militares, en el gobierno y en el accionar de las instituciones en general. La película en cuestión, narra los hechos de una familia (madre, padre y dos hijos: una bebé y un niño de 12 años) exiliada en La Habana que regresa a la Argentina en el año 1979, en plena dictadura militar. Los padres militan en la agrupación Montoneros ${ }^{3} y$, para sobrevivir en este contexto de persecución política, ocultan su verdadera identidad. El foco se centra en el niño, Juan, que cambia su nombre por el de Ernesto (en alusión al Ernesto "Che" Guevara). De allí el título "Infancia clandestina", que alude a una niñez que transcurre entre ocultamientos, huidas, cambios de identidad pero también en actividades cotidianas que comparten como cualquier otra familia: el niño asiste a la escuela, se va de campamento, se enamora, festeja su cumpleaños, etc.

En tanto al largometraje Machuca (2004), la historia se sitúa en Santiago de Chile en 1973, momento en que se produce la última dictadura militar en ese país. Los protagonistas son dos niños de 11 años de contextos completamente diferentes: Gonzalo vive en un barrio residencial y Machuca en El Esfuerzo, un asentamiento marginal ubicado a pocas manzanas del colegio Saint Patricks, institución privada, religiosa, con elevado prestigio social. El director de dicho colegio, con el apoyo de algunos padres, intenta integrar a chicos procedentes del poblado y lo hace pese a la oposición de otro grupo de padres que pregonan que las "las diferentes clases sociales no han de mezclarse". Esta nueva situación del colegio permite el encuentro entre los dos niños y el nacimiento de una amistad, aunque el Golpe de Estado que se produce en 1973, que nombra a un interventor militar para la dirección del colegio, marca no sólo el inicio del fin de una experiencia de inclusión y reforma, sino también una polarización social que se manifiesta en la amistad trunca de los niños protagonistas. 
El último filme seleccionado, $O$ ano em que meus pais saíram de férias (2006), traducido al español como El año que mis padres se fueron de vacaciones, ofrece una mirada singular sobre la vida de Mauro, un niño de 12 años de clase media de Minas Gerais, hijo de militantes de izquierda. Está ambientada en el Brasil de 1970, contexto revolucionado para el mundo entero, pero la mayor preocupación en la vida de Mauro tiene poco o nada que ver con la proliferación de dictaduras militares en Sudamérica: su mayor sueño es ver cómo Brasil gana por tercera vez el mundial de fútbol. Su vida cotidiana se ve alterada cuando sus padres deben irse del país y él queda a cargo de su abuelo paterno, a quien le ocurre algo inesperado y el niño es abandonado a su suerte sin poder informar a sus padres. Es finalmente Shlomo, un viejo judío solitario y empleado de la sinagoga local, vecino de su abuelo, el que se encarga de él.

El hecho de rescatar las acciones cotidianas, el núcleo familiar y la vida personal de un niño, y su punto de vista como el eje argumentativo, ubica a estas películas en la línea de otros films que relatan procesos históricos en contextos atravesados por la violencia política. Nos referimos a Cría Cuervos de Carlos Saura (1975, España), Kamchatka de Marcelo Piñeyro (2001, Argentina-España), La culpa es de Fidel de Julie Gavras (2006, Francia), El laberinto del fauno de Guillermo del Toro (2006, España-México), El niño de pijama a rayas de Mark Herman (2008, Irlanda, Reino Unido y Estados Unidos), entre otras.

Como ya expresamos, las películas Infancia clandestina, Machuca y $O$ ano em que meus pais saíram de férias otorgan, a nuestro entender, una mirada que puede ser inscrita entre aquellos films que contienen elementos del género autobiográfico. Si bien los directores de los tres films no reconocen a sus películas como específicamente autobiográficas, manifiestan retomar en ellas vivencias propias para luego incorporar elementos y datos que no se corresponden con la realidad, abriendo el juego entre narraciones autobiográficas y elementos ficcionales, cuestión que abordaremos más adelante. Se trata de historias que están basadas en contextos vividos por los directores durante su infancia. En el caso de Benjamín Ávila, hijo de madre desaparecida, actual militante de la agrupación H.I.J.O.S, que nuclea a los hijos de los desaparecidos de la última dictadura militar argentina. Ávila rescata experiencias, vivencias y sentimientos de su infancia y crea la historia de Juan (el personaje de la película), un niño 
hijo de militantes, haciendo hincapié en sus vivencias, sentimientos, temores y experiencias.

Por su parte, Andrés Wood recupera un experimento real realizado en la época del gobierno socialista de Salvador Allende en el Saint George's College, colegio al que director asistió y que tuvo la particularidad de ser el único colegio privado de Santiago de Chile intervenido en la Dictadura de 1973. En este colegio, el Padre Gerardo Whelan a principios de la década de 1970 introduce la Teología de la Liberación y desde entonces tiene la reputación de ser una institución activista social y política. Una de sus primeras medidas fue la inclusión de niños de clases populares para promover la tolerancia, convivencia y respeto entre las diferentes clases sociales. En el caso de Cao Hamburger, en 1970, al igual del resto del equipo con el que trabajó este film, estaba transitando su infancia y fue testigo del momento en que sus padres eran detenidos durante la última dictadura cívico-militar. De esta manera, en los relatos fílmicos seleccionados, los directores retoman elementos de su propio pasado y los recrean, provocando una construcción novedosa que conjuga lo vivido, elementos ficcionales y la perspectiva desde el presente. Así, se crea un nuevo tiempo: el ahora, que, desde la mirada de Benjamin, ${ }^{4}$ es producto de la conjunción entre experiencias pasadas y vivencias del presente, a partir de las que se produce una rememoración de ese pasado.

De este modo, los filmes en cuestión componen una forma de representar el pasado, teniendo la particularidad de ser narrados desde la óptica de niños, lo cual nos resulta interesante porque se trata de la creación de un microcosmos histórico que pone el acento en la dimensión cultural y en aspectos políticos muy diferentes a la visión proporcionada tradicionalmente por versiones académicas, fílmicas y documentales más consagradas.

\section{ENTRE LA Historia Y LA FICCIÓN:}

\section{EL CINE CON ELEMENTOS AUTOBIOGRÁFICOS}

El cine, como séptimo arte, ocupa un lugar importante en la historia contemporánea, recreando lo colectivo, recuperando sueños, deseos y esperanzas de gran parte de la humanidad. Así, podemos afirmar que la narrativa fílmica, combinada con elementos autobiográficos, habilita un fenómeno de identificación entre el director y el espectador. En este sentido, Felipe y Teruya (2009) 
introducen la idea de que, al revelar su intimidad y sus secretos, el cineasta crea un clima de amistad, de familiaridad que nos permite identificarnos con él. Asimismo, los autores invitan a entender al cine como práctica cultural que exige comprender lo que está dicho y sus silencios, aquello que está insinuado, considerando que existe un mensaje pero que no llegará a cada espectador de la misma manera. De este modo, el significado de los mensajes es producto de una interacción entre el cineasta y el espectador, el cual se erige como un sujeto social, que interpreta, se emociona, se identifica y otorga sentido.

Igualmente, puede considerarse el cine como "un documento sobre las formas de representación del mundo. El cine de ficción como documento histórico puede responder, fácilmente, a algunas de las cuestiones que se encuentran en continuo movimiento en nuestro presente" (Quintana, 2003, p.268).

De este modo, constituye un elemento que nos permite establecer relaciones entre el presente y el pasado, ya que se convierte en una fuente para acceder a las ideas y perspectivas de determinados actores sociales en diversos contextos históricos. De este modo, cabe resaltar que el cine, al igual que las imágenes fijas o cualquier fuente documental, está lejos de ser un reflejo de la realidad sino que es una representación, una construcción de lo sucedido, condicionada por las ideas y los objetivos del cineasta. Este último aspecto se ve reflejado en las afirmaciones del director de Machuca, quien vivió, siendo niño, la pérdida de la democracia en Chile y, mediante el film, intenta recuperar esa mirada pueril para retratar el proceso:

En Machuca he retomado ese período desde la melancolía, pero no lánguida sino llena de entusiasmo, como el de dos niños de once años que descubren mundos externos e internos en los que por fin pueden sentirse a sus anchas. Todo se vive literalmente desde sus ojos. A través de ellos recibimos la información fragmentada del experimento educacional, de sus familias y del país. ${ }^{5}$

Así, la ficción cinematográfica se convierte en un documento histórico ya que nos permite vislumbrar los motivos, perspectivas y valores en los cuales se inscribe la reconstrucción de los sucesos. Acordamos con Efrén Cuevas (2012) en que el cine autobiográfico permite mirar el pasado desde el presente de la escritura y del montaje, construyendo, reevaluando y dotando de sentido el relato de vida del propio cineasta. Esto implica otorgar a lo filmado una "perspectiva retrospectiva”, que según Lejeune es la condición básica de la empresa 
autobiográfica. ${ }^{6}$ Así, el cine autobiográfico se presenta con una estructura propia, basada en dimensiones temporales que no existen en el medio escrito. Cuevas (2012) señala tres temporalidades: por un lado, encontramos las imágenes y sonidos filmados en un tiempo concreto, que coincide con el presente inmediato de los acontecimientos registrados y con escenas de la vida cotidiana del cineasta. Por otro lado, se encuentra la mirada retrospectiva autobiográfica del realizador, que ordena esas escenas en el montaje y puede incorporar músicas y otros elementos del discurso autobiográfico escrito. En cuanto a la tercera temporalidad, es aportada por los materiales autobiográficos visuales o sonoros recuperados del pasado, como las fotos, películas domésticas del archivo familiar y otros acervos históricos de dominio público. En relación a ello, se puede afirmar que las diversas tramas temporales se reconstruyen y conjugan con las trazas filmadas del pasado.

De este modo, en el cine autobiográfico se pone en juego la transformación de lo privado e íntimo en asunto público, en exhibición, se hace de la subjetividad una vía de indagación, construyendo una versión de la realidad, asumiendo de esta manera que no es posible referirnos en este punto a una "verdad absoluta", sino más bien a la composición de una historia que revela el punto de vista de cada cineasta. En palabras de Núnez (2011), se produce un vaivén entre lo privado y lo público, porque si bien se rescatan cuestiones personales, vivencias propias, también se develan memorias e historias de relaciones sociales más amplias.

Las películas seleccionadas se nutren del cine autobiográfico, tomando elementos de este género para reconstruir el pasado reciente de la Historia argentina, chilena y brasileña. Cabe señalar que al hablar de Historia debemos considerar que se trata de una construcción de ciertas versiones sobre el pasado, que envuelve tanto olvidos como recuerdos (Albuquerque Júnior, 2012). Es decir, si bien los acontecimientos surgen como consecuencia de la acción, no es el actor sino el narrador quien "hace" la Historia (Arendt, 2009). En palabras de Viñao, todos, sin excepción, recreamos el pasado y mezclamos recuerdos y olvidos. La memoria no es un espejo, sino un filtro, y lo que sale, a través de él, no es nunca la realidad misma, pues ha sido recreada, reinterpretada y a veces, incluso, consciente e inconscientemente imaginada hasta el punto que puede llegar, en la mente del que recuerda, a sustituir, con ventaja, a lo realmente acaecido ... frente a la natural tendencia individual o colectiva 
a recrear, imaginándoselo, su propio pasado, se halla el quehacer histórico que lo recrea, reconstruyéndolo - también parcialmente - y reinterpretándolo (Viñao, 1999, p.83). En cierto sentido, los realizadores de los films escriben una historia, estableciendo una producción de subjetividad, convirtiendo al relato en una construcción personal. Asimismo, no debemos olvidar que es una escritura de sus propias vivencias, de su infancia, realizada con el tamiz de los ojos del presente. Como expresa Albuquerque Júnior (2012) la escuela de los Annales ha insistido en el hecho de que la Historia se hace desde y para el presente. En este sentido, es factible pensar que las películas en cuestión responden a un contexto de realización preocupado por rescatar la memoria o al menos un sentido de ella. Debemos reflexionar que, además de ser una evocación del pasado y de servir como vehículo de memoria, poseen un carácter de reactualización y de resignificación a partir de las cuestiones del presente.

En este sentido, al trabajar con relatos autobiográficos o testimonios, lo realmente importante es la visión que posee el narrador de los hechos o la resignificación que da a su historia y al modo de contarla. En una entrevista realizada a Andrés Wood, el director sostiene que hacer Machuca:

Fue un proceso muy entretenido, por un lado porque hubo que rescatar de la memoria ... Yo viví una experiencia similar, en un colegio muy parecido, con personajes muy parecidos. Y ese intento justamente de meter en una misma historia recuerdos fascinantes, muy llenos de vida y de alegría, con una mezcla de tristeza, por el entorno en el que está sucediendo ... Descubrir a los niños, hacer actuar a los niños, revivir esa época. Fue uno de los procesos cinematográficos más intensos que he vivido. ${ }^{8}$

En el caso de Infancia clandestina, el director se basa en su propia historia de vida al narrar los acontecimientos y pide la aprobación del guión a personas que vivieron en la época señalada, como las Abuelas de Plaza de Mayo y otros militantes de Montoneros. Como afirma Cabral da Silva, la literatura de testimonio intenta contar una situación vivida "em um contexto de dor, humilhação, ofensa, na tentativa de, por um lado, elaborar a situação-limite vivida e, por outro, ser capaz de esquecê-la, para que, neste movimento, a vida possa seguir o curso interrompido" (Cabral da Silva, 2005, p.2). Esta idea se refleja en la entrevista realizada a Cao Hamburger, quien sostiene que lo que se pretende con la elección de cámaras para la creación del ambiente del film es 
transmitir una calidez al espectador. En palabras del cineasta "Hay un cierto aire subjetivo que le da a la película un aire testimonial, no es una cámara plana". ${ }^{9}$ Resulta interesante también rescatar la forma en que Wood recrea su infancia en el film: "A mí lo que me gustó de la película es que no va con rabia a esos años, sino que va, aprovechando que está contada desde el punto de vista de un niño, como diciendo 'bueno, algo pasó y se cuenta'. No se cuenta con mala intención". ${ }^{10}$

Cao Hamburger, por su parte, explicita claramente que no se trata de una película autobiográfica, pero que aun así se toman algunos elementos del pasado del cineasta y su colega. Asimismo, la relación entre memoria e imaginación se pone en funcionamiento cuando señala "La película no es autobiográfica, pero el guión contiene algunos de mis recuerdos, además de los de Claudio, coguionista. Fragmentos de esos recuerdos están ahí. Todos trabajamos en sintonía con nuestra memoria". ${ }^{11}$

Del mismo modo, el entrecruzamiento entre datos autobiográficos con elementos ficcionales es posible de observar en la entrevista realizada al director del film Infancia clandestina en el programa de televisión "Con sentido público". ${ }^{12}$ En esta entrevista, el director se refiere al modo en que los elementos ficcionales se entrecruzan con datos reales: "cuando sucedió la historia real, vivida, yo tenía siete años y mi hermano mayor tenía ocho”. Luego, con el coguionista deciden incorporar al personaje en el cuerpo de un niño de doce años. Así, se evidencia que "un mismo relato puede alterar los nombres, fechas, lugares e incluso circunstancias y ser, sin embargo, veraz en la vivencia de lo narrado" (Viñao, 1999, p.83). En la narración que Ávila construye, se reflejan estas alteraciones en cuestiones como la edad del personaje, el hecho de que en la película aparecen sus padres como protagonistas mientras en la vida real era su madre y la pareja. Estas transformaciones también son evidentes en el desenlace de la historia, el cual ofrece una resolución diferente a la vivida por el director cuando niño.

En relación a lo anterior, cabe señalar que en una obra de ficción siempre existe contenido autobiográfico, lo cual se hace evidente tanto en los films como en los relatos de los directores en las entrevistas analizadas. En palabras de Viñao:

La imaginación siempre interviene. Y el olvido. La memoria humana es, por ello, un proceso dinámico. Está en permanente reconstrucción. Posee una naturaleza 
transformadora, recreativa y omnipresente. Reaparece, quiérase o no, mezclada con la ficción. Y viceversa. De ahí que lo autobiográfico aflore siempre ... en toda obra de ficción. De ahí también que, junto a ello, en esta amalgama de recuerdos y ficción, de sensaciones e imaginación, operen los silencios y los olvidos, los disfraces y enmascaramientos. (Viñao, 1999, p.83)

En este sentido, el citado autor sostiene que en las obras de ficción, la imaginación y la fantasía no tienen otro límite que aquel que les impone - o intenta imponer - el propio escritor. Se puede afirmar que en toda literatura de ficción hay elementos autobiográficos que se vinculan con anécdotas reales. Así, la invención surge a partir de la memoria: "A la hora de escribir, memoria e imaginación se confunden siempre de tal forma que el resultado es una ficción. Es muy difícil atenerse exclusivamente a la memoria porque la imaginación siempre interviene" (Viñao, 1999, p.83).

Como ya señalamos, otra de las cuestiones que entrama el relato de las películas escogidas es la relación entre el pasado reciente y su resignificación desde el presente. Este aspecto queda evidenciado en el siguiente fragmento de la entrevista realizada a Ávila:

Al principio lo que más trabajamos ... fue en tratar de que dejara de ser una película autobiográfica, yo tenía muy claro desde el principio que no quería contar mi historia, que estuviera basada en mi historia ... Si yo hubiera hecho una película autobiográfica el tema hubiera sido otro, claramente. Y yo tenía muy claro qué cosas quería contar, de qué cosas quería hablar sobre esta época en que viví y este distanciamiento con mi propia historia, este trabajo de construir una película, no un reflejo de mi propia experiencia, que creo que ayuda a tener una historia cinematográfica. ${ }^{13}$

Sobre este aspecto, Cao Hamburger afirma: "La película cuenta mucho sobre los tiempos en que yo, Claudio, Braulio, Anna, Cassio, y otros miembros del equipo éramos niños. No muy diferentes a Mauro, también teníamos una visión fragmentada de la realidad. En cierto modo se cuenta nuestra historia”. ${ }^{14}$ Y en relación al filme chileno, en una entrevista ${ }^{15}$ Wood menciona que en Machuca él cuenta parte de su historia, de su paso por un colegio privado que intentó mezclar diferentes clases sociales hasta que fue intervenido por los militares. Así, podemos ver el complejo entramado existente entre memoria, autobiografía y cine, ya que se pone en marcha una triangulación que permite 
analizar la visión histórica que aparece como telón de fondo de la reconstrucción fílmica.

Como queda evidenciado, en los films seleccionados aparecen también elementos que nos remiten a una experiencia intensa, transformadora, traumática, vivenciada por los niños, hoy adultos, cuyas experiencias y perspectivas se constituyen el foco de la narración. En un artículo anterior trabajamos sobre la experiencia de trauma (autores, 2013), como necesidad de liberación interior para el cineasta, como "redención" de una situación vivida en el pasado. Coincidimos con Bustamante en que la realización de un filme contiene "ciertos rasgos terapéuticos" (Bustamante, 2011, p.127). Este aspecto aparece claramente en la entrevista a Benjamín Ávila:

de algún modo era una deuda que yo me debía con mi propia historia, tenía que ver más con mi familia ... es una película que yo sabía que era inevitablemente dramática porque la historia era dramática, nunca la trabajamos desde ese tono ... la historia es dramática pero la película no la vivimos en un tono dramático ... me parece que la risa y el humor es lo que yo recordaba mucho de cuando era chico.

De los tres directores seleccionados, Ávila es quien expresa haber vivido una situación de mayor complejidad durante la dictadura, por lo cual podríamos inferir que ha logrado canalizar la experiencia traumática vivenciada en su infancia a través de una producción artística. Y al respecto de su experiencia, el director sostiene:

lo traumático es la violencia, lo traumático era la ausencia, lo traumático es para mí que me hayan sacado a mi hermano que yo recuerdo que me hayan sacado a mi hermano eh...que me hayan llevado, que me hayan interrogado ... eso sí fue traumático, extremadamente traumático, donde el miedo se instauró en el proceso más íntimo de mi personalidad. ${ }^{16}$

Lo anteriormente expuesto nos lleva a reflexionar y a plantearnos algunos interrogantes que, lejos de crear certezas abren nuevas cuestiones: ¿Qué papel estaría cumpliendo el cine como medio artístico donde se canalizan un conjunto de experiencias personales y al mismo tiempo sociales, históricamente situadas? ¿Cuál es el límite entre el contenido autobiográfico, lo ficcional, la 
memoria y la construcción de versiones sobre un pasado reciente cuyas heridas aún siguen sangrando?

\section{CINE Y ESCUELA: EDUCANDO LA MIRADA}

Luego de analizar la relevancia del género autobiográfico en el cine, quisiéramos detenernos en la importancia de su inclusión como herramienta de trabajo en las clases escolares. Sostenemos que su significatividad puede radicar en ayudar a comprender cómo las personas resignifican los hechos históricos desde el presente, haciendo hincapié en la reconstrucción de aquellos acontecimientos que han marcado la historia personal y configuran la memoria colectiva. En este sentido, creemos que sería interesante poder abordar el cine y sus aspectos autobiográficos en las escuelas, teniendo como base la disponibilidad de recursos tecnológicos que nos permiten acceder a diferentes películas y a proyecciones grupales, abriendo la posibilidad de establecer usos creativos y significativos con los alumnos.

Cuando nos referimos a usos significativos, hablamos de trabajar el cine como fuente, haciendo hincapié en el contexto de realización del film, las intenciones del mismo, focalizando en los aspectos objetivos y subjetivos que lo conforman, utilizando el cine como formador del "gusto", en el sentido dado por Bergala (2007). Desde la perspectiva del citado cineasta, el gusto es aquello que nos habilita a distanciarnos de los films mayormente distribuidos por la industria comercial, que no tienen ninguna preocupación ni respeto por la formación del gusto de los espectadores, sino que más bien están enfocados en el consumo de sus productos.

En sintonía con la idea señalada, creemos que la escuela es el espacio propicio para que los alumnos puedan tener acceso a películas que se distancien de las de mayor circulación en el mercado. Si pensamos en un cine que "nos abre los ojos, los coloca a la distancia justa y los pone en movimiento" (Larrosa, 2006, p.115) tenemos que considerar que la educación de la mirada tiene que ser muy respetuosa, para no opacar la creatividad de quien mira. Este es un desafío para los educadores, ya que resulta necesario respetar las reacciones de los estudiantes frente al cine, sus interpretaciones y silencios. Es decir, muchas veces los niños hacen silencio a la vez que expresan en gestos y con su rostro su propia mirada sobre las cosas y esto es lo que desestabiliza a 
los adultos, enfrentarse a ese silencio. El silencio no permite develar el sentido, el significado de esa mirada, imposibilitando la sensación de seguridad y eso incomoda a los adultos. Por lo tanto, la educación de la mirada es posible si, como adultos, aceptamos las reacciones que posiblemente no sean las esperadas, pero que sin duda tienen que ver con el encuentro entre ellos y esas películas que tal vez siquiera sabían que existían. En este sentido, es la escuela la que puede cumplir un rol central en iniciar el vínculo entre los estudiantes y la obra de arte, sin olvidar que existe un placer individual y una forma única de encontrarse con el arte, de interpretar una obra.

Por lo tanto, la experiencia con el cine no es algo enseñable porque el arte no se enseña, se experimenta, se encuentra. En palabras de Bergala, el arte

se transmite por vías diferentes del discurso del saber único, y a veces, incluso sin ningún tipo de discurso. El quehacer de la enseñanza es la regla, el arte debe ganarse un lugar de excepción dentro de ella ... el arte debe seguir siendo una experiencia dentro de la escuela, a través de la cual los alumnos entren en contacto con su alteridad radical. (Bergala, 2007, p.34-35)

De manera que, una propuesta interesante sería que la escuela brinde las condiciones para que ese encuentro se produzca, considerando que es el espacio propicio con el que la mayoría de los estudiantes cuenta para conocer y acceder a obras o elementos que se alejan tanto de la órbita tradicional y/o comercial como de los recursos más comunes y propios del mercado.

Considerando que gran parte de las escuelas argentinas cuenta con diferentes recursos que posibilitan el acercamiento a una gran variedad de películas, se podría apostar a que no sólo sean espectadores de cine sino que también puedan crearlo. La Pedagogía de la Creación (Bergala, 2007), afirma que lo importante es experimentar, vivir la experiencia. Esto implica que los alumnos realicen el pasaje al acto de filmación, sólo por el hecho de la importancia de vivir esa experiencia, ya que algo sucede a nivel corporal y cerebral que no puede adquirirse con el análisis de películas.

Es necesario mencionar aquí que este cambio de abordaje no se logra intercambiando el pizarrón por una pantalla, de nada nos serviría pensar el cine en la escuela si las prácticas cotidianas responden a otros esquemas, donde lo que varía es sólo el recurso y no las prácticas ni los significados que las configuran. Se podría decir que se necesita "reinstalar el cine en el imaginario 
escolar y pensarlo como algo más que un simple recurso didáctico" (Paladino, 2006, p.143). Esto implica pensar al cine no sólo como estímulo espontáneo del interés y la curiosidad de los estudiantes sino como una obra que fomente el encuentro con la Historia, con la memoria colectiva partiendo de perspectivas alternativas, de narrativas con elementos autobiográficos como las ofrecidas por las películas analizadas, propiciando la educación de la mirada, en el sentido conferido por Inés Dussel (2006). Desde la perspectiva de la autora, educar la mirada implica liberar nuestra propia óptica, ubicar la atención sobre el mundo, siendo consciente del lugar que ocupamos en él para poder actuar sobre la realidad, de una manera crítica. En su estudio sobre el cine en la infancia, Larrosa (2006) apela a la importancia del cine para educar la mirada, precisarla, ajustarla, ampliarla, multiplicarla, inquietarla, ponerla a pensar. Así, la liberación de la mirada deriva en una transformación personal, un cambio en nosotros mismos y en el tiempo en que vivimos; de ahí que la escuela cumpla un rol fundamental en enseñar a mirar de esta manera, trascendiendo la fugacidad de las imágenes, intentando evitar la banalización y naturalización de las mismas. Así, se trata de fomentar una pedagogía que eduque la mirada, que la interpele desde el pensamiento, que enseñe a ver otros objetos o nuevas formas de mirar los ya existentes, ubicando a la escuela como lugar de encuentro y contacto con un mundo-otro, desconocido, buscando entender y desafiar nuestros propios límites, lo que nos vuelve más abiertos a los otros y a nosotros mismos.

\section{Consideraciones finales}

En este artículo buscamos reflexionar sobre el modo en que el cine con elementos autobiográficos permite mirar el pasado desde la escritura y el montaje realizado desde el presente, construyendo, reevaluando y dotando de sentido el relato de vida del propio cineasta, su experiencia individual, la de todos aquellos que protagonizaron los acontecimientos y la memoria de la sociedad de la cual forma parte. Así, el cine se erige como el catalizador de las relaciones entre pasado y presente estableciendo una mirada retrospectiva sobre la tradición, la herencia y el pasado para continuar con la construcción de la memoria colectiva, partiendo de una experiencia subjetiva. De este modo, otra de las cualidad del cine con elementos autobiográficos es la de establecer el eje 
narrativo en un microcosmos, rescatando las acciones cotidianas, el núcleo familiar y la vida personal de un niño, pudiendo así reflejar el contexto social, político y cultural en el que se inscribe la historia personal. Así, se obtiene una visión de la realidad sobre la cual no pesa la importancia de establecer su veracidad o falsedad sino más bien, la posibilidad de determinar desde dónde se construye esa versión de la Historia, permitiendo develar el punto de vista del cineasta.

De este modo, en todas las versiones de la Historia conviven recuerdos y olvidos, ya que la memoria es un filtro que permite recrear la realidad, reinterpretarla, ofreciendo versiones parciales de lo sucedido, incluyendo recuerdos nunca acaecidos, resaltando aquello personalmente significativo y relegando al olvido parte de lo sucedido. En esta reconstrucción también se reelaboran los propios recuerdos a partir de memoria colectiva, considerando que en casos como las dictaduras militares, las situaciones traumáticas vividas por quienes hoy se convierten en testigos fundamentales, provocan que los recuerdos de unos se conviertan en recuerdos de otros que vivenciaron los mismos momentos, derivando en la creación de recuerdos colectivos.

En torno a la construcción de la memoria colectiva cabe preguntarse ¿dónde empieza y dónde termina la ficción y cuál es su interrelación con la realidad? Asimismo, nos interrogamos e invitamos a pensar sobre los posibles aportes que la escritura y el montaje autobiográfico pueden realizar en la discusión en las escuelas sobre la construcción de la memoria colectiva. Desde nuestro punto de vista, nos resulta interesante proponer al cine con elementos autobiográficos como un recurso artístico que trasciende la consideración de las películas como reflejo de los hechos tal cual sucedieron, centrándose en el cine como fuente histórica, como lugar de construcción de la memoria, ubicando la reflexión en un terreno más fecundo que permita una triangulación más significativa entre memoria, autobiografía y cine.

\section{REFERENCIAS}

ALBUQUERQUE JÚNIOR, Durval Muniz. Fazer defeitos nas memórias: para que servem o ensino e a escrita da história? In: GONÇALVES, Márcia de A. et al. (Org.) Qual o valor da história hoje? Rio de Janeiro: Ed. FVG, 2012.

ARENDT, Hannah. La condición humana. 1.ed. 5.reimp. Buenos Aires: Paidós, 2009. 
BERGALA, Alain. La hipótesis del cine en la escuela. Barcelona: Laertes, 2007.

BUSTAMANTE, Emilio. Rostros y máscaras: notas sobre objetividad y autobiografía en el cine documental. Pterodactilo. Department of Spanish and Portuguese. The University of Texas at Austin, 2011 Disponible en: http://pterodactilo.com/cuatro/Bustamante.pdf; Consulta: 14 feb. 2013.

CABRAL DA SILVA, Marcia. Primo Levi: notas sobre literatura de testemunho. Revista Vivença, Brasil: UFRN, n.29, p.65-74, 2005.

CUEVAS, Efrén. El cine autobiográfico en España: una panorámica. RILCE - Revista de Filosofía Hispánica, España: Universidad de Navarra, n.28, p.106-125, 2012.

DUSSEL, Inés. Educar la Mirada: Reflexiones sobre una experiencia de producción audiovisual y de formación docente. In: DUSSEL, Inés; GUTIERREZ, Daniela (Comp.) Educar la mirada: políticas y pedagogías de la imagen. Buenos Aires: Ed. Manantial; Flacso; OSDE, 2006. p.277-294.

FELIPE, Delton; TERUYA, Teresa. Narrativas filmicas na educação escolar: construindo processos de alteridade. In: SEMINARIO DE PESQUISA DE PPE. Maringá, PR: Programa de pós-graduação em educação, Universidade Estadual de Maringá (UEM), 2009. Disponible en: www.ppe.uem.br/publicacoes/seminario_ ppe_2009_2010/pdf/2009/18.pdf; Último acceso: 9 mayo 2015.

GREGORINI, Vanesa; MARTINO ERMANTRAUT, Sabrina. Autobiografía y Ficción en el cine. Letras de hoje (Estudos e debates de assuntos de linguística, literatura e língua portuguesa. Programa de Pós-Graduação em Letras. Faculdade de Letras, Pontifícia Universidade Católica do Rio Grande do Sul), Porto Alegre: Ed. PUCRS, v.48, n.4, p.484-492, out./dez. 2013.

HUARTE, Gabriel. Naturaleza del conocimiento histórico. Su enseñanza y aprendizaje. Pedagogía y saberes, Bogotá: Universidad Pedagógica Nacional, p.63-73, 2006.

LARROSA, Jorge. Niños atravesando el paisaje. Notas sobre cine e infancia. In: DUSSEL, Inés; GUTIÉRREZ, Daniela (Comp.) Educar la mirada: políticas y pedagogías de la imagen. Buenos Aires: Ed. Manantial; Flacso; OSDE, 2006. p.113-134.

NÚNEZ, José Walter. Memoria e identidad: algunas dimensiones del yo y del otro en la narrativa fílmica de Andrés Di Tella. In: SIMPÓSIO NACIONAL DE HISTÓRIA, 26. Anais... São Paulo: Anpuh, 2011.

PALADINO, Diana. Qué hacemos con el cine en el aula. In: DUSSEL, Inés; GUTIÉRREZ, Daniela (Comp.) Educar la mirada: políticas y pedagogías de la imagen. Buenos Aires: Ed. Manantial; Flacso; OSDE, 2006. p.135-144.

QUINTANA, Ángel. Fábulas de lo visible: el cine como creador de realidades. Barcelona: Acantilado, 2003.

VIÑAO FRAGO, Antonio. Las autobiografías, memorias y diarios como fuente histórico-educativa: tipología y usos. Sarmiento, n.3, p.223-253, 1999. Disponible 
en: http://ruc.udc.es/dspace/bitstream/2183/7729/1/SAR_3_art_9.pdf; Consulta: 2 mar. 2013.

\section{Entrevistas referenciadas}

Escribe Andrés Wood: Machuca, con melancolía y entusiasmo (3 ago. 2004). Disponible en: www.abcguionistas.com/noticias/articulos/escribe-andres-wood-machuca-con-melancolia-y-entusiasmo.html

Entrevista - Andrés Wood, director de Machuca: El nuevo cine chileno por Jorge de Elizalde (7 out. 2005). Disponible en: www.imaginacionatrapada.com.ar/Cine/entandreswood.htm

Entrevista - Andrés Wood. Por Lorena Cancela. (jun. 2014). "Vengo de una generación en la que era imposible estudiar cine en Chile". Disponible en: http://tierraentrance.miradas.net/2014/06/entrevistas/vengo-de-una-generacion-en-laque-era-imposible-estudiar-cine-en-chile-entrevista-con-andres-wood.html

Entrevista - Benjamín Ávila y Teo Gutiérrez. Con sentido público: Infancia clandestina. TV Pública, Argentina. (18 set. 2012). Disponible en: www.youtube.com/wat$\mathrm{ch} ? \mathrm{v}=\mathrm{QMqI786z4j \textrm {c }}$

Entrevista - Cao Hamburger (4 mayo 2011). Disponible en: www.thecult.es/Critica-de-cine/el-ano-que-mis-padres-se-fueron-de-vacaciones-o-ano-em-quemeus-pais-sairam-de-ferias-2008/Entrevista-con-en-Cao-Hamburger.html

\section{Films analizados}

Infancia clandestina, de Benjamín Ávila. Argentina, 2011.

Machuca, de Andrés Wood. Chile, 2004.

O ano em que meus pais saíram de férias, de Cao Hamburger. Brasil, 2006.

\section{NOTAS}

${ }^{1}$ Nos referimos a las dictaduras militares que ocuparon el poder entre 1964 y 1985 en Brasil, entre 1976 y 1983 en Argentina y entre 1973 y 1990 en Chile.

${ }^{2}$ Desde la perspectiva de Huarte, la narrativa se define como un modelo explicativo en el cual se intenta: comprender las acciones de los hombres expuestas a través del relato, captar las acciones, los agentes y sus consecuencias en un contexto social dado y dar cuenta de la experiencia humana dentro de un contexto. Huarte, 2006.

${ }^{3}$ Montoneros fue una organización guerrillera argentina que se identificaba con la izquierda peronista. Desarrolló la lucha armada entre 1970 y 1979. 
${ }^{4}$ Benjamin cit. en NÚNEZ, 2011, p.6.

${ }^{5}$ Escribe Andrés Wood..., 2004.

${ }^{6}$ Cit. en CUEVAS, 2012, p.107.

${ }^{7}$ COMOLLI, cit. en NÚNEZ, 2011, p.4.

${ }^{8}$ Entrevista - Andrés Wood, 2005.

${ }^{9}$ Entrevista - Cao Hamburger, 2011.

${ }^{10}$ Entrevista - Andrés Wood, 2005.

${ }^{11}$ Entrevista - Cao Hamburger, 2011.

${ }^{12}$ En la entrevista participan Benjamín Ávila, director de la película Infancia clandestina y Teo Gutiérrez Moreno, actor protagonista de la misma. La conversación gira en torno a la trama, de cómo era el momento histórico en el que sucede la historia, de la experiencia durante la filmación y de su estreno cine. Entrevista - Benjamín Ávila y Teo Gutiérrez, 2012.

${ }^{13}$ Entrevista - Benjamín Ávila y Teo Gutiérrez, 2012.

${ }^{14}$ Entrevista - Cao Hamburger, 2011.

15 "Vengo de una generación en la que era imposible estudiar cine en Chile". Entrevista Andrés Wood, 2014.

${ }^{16}$ Entrevista - Benjamín Ávila y Teo Gutiérrez, 2012.

Artigo recebido em 29 de maio de 2015. Aprovado em 2 de julho de 2015. 